\title{
FACULTY AND ADMINISTRATOR PERCEPTIONS OF THEIR ENVIRONMENTS: Different Views or Different Models of Organization?
}

\author{
Marvin W. Peterson and Theodore H. White
}

Individuals' perceptions of the culture and climate of the organizations in which they work influence their motivation and individual performance. Using a theoretical model of institutional culture, organizational climate, and faculty motivation, this study examines how faculty and academic administrators differ in their perceptions; whether these differences in perceptions are affected by institutional type; and to what extent faculty and administrators have different implicit models of their institutions (i.e., see different organizational variables as predictors of faculty motivation and involvement). The goals of this investigation are to shed additional light on the relationship between institutional variables and faculty performance, to examine the existence of differing implicit models, and to provide new insights for administrators in managing their postsecondary institutions.

Managers who work with each other often use "implicit models" composed of their own somewhat subjective and biased views of the managerial problem. Such implicit models create a great deal of difficulty in resolving differences. . . Organizational models filter and focus perceptions. They underlie and guide our perceptions about organizations. (Tichy, 1983, pp. 39-40).

Numerous studies of colleges and universities have consistently identified differences between administrator and faculty perceptions of their institutions (White, 1990). Except for the commonly held assumption that colleges and

Marvin W. Peterson and Theodore H. White, University of Michigan, 2117 School of Education, 610 East University, Ann Arbor, MI 48109.

The research reported in this paper is part of the Research Program on The Organizational Context for Teaching and Learning in the National Center for Research to Improve Postsecondary Teaching and Learning (NCRIPTAL). The research is supported by a grant from the Office of Educational Research and Improvement (OERI), U.S. Department of Education (ED), to the University of Michigan (grant number G008690010). The opinions expressed herein are those of the authors and do not necessarily reflect the position or policy of the OERI/ED or the Regents of The University of Michigan, and no official endorsement should be inferred. 
universities should have common purposes (Corson, 1960) and that the faculty and administrator constituencies must work together effectively to achieve those purposes, the implications of these differences are seldom examined and may be substantial. A critical implication is the observation raised by Tichy that different managers (or constituent groups) in an organization may not only have different views, but may have different "implicit (organizational) models" of how their institutions function. In summarizing extensive literature and research on leadership in higher education, Bensimon (1987) emphasized the importance for administrators of recognizing multiple "cognitive frames" or different implicit models of how their institutions functioned:

Leaders who incorporated elements of several frames are likely to be more flexible in responding to different administrative tasks because they are able to enact different images of the organization and provide different interpretations of events. (p. 4)

This belief suggests that perceptions of different constituent groups may reflect more than just consistent differences and may reflect different "implicit models" of how their institution functions. Thus, if two groups hold very different "cognitive" or implicit models of how their institution functions, they may assume different variables influence key dependent variables. For example, if administrators have a hierarchical, rational model, they may assume that obtaining board approval (authoritative power) and rationally distributing salary increments (financial rewards) may enhance faculty commitment to the enterprise. Faculty, on the other hand, may have a professional collegial model assuming that peer agreement (consensual power) and recognition (professional status) may enhance their commitment. Thus, their disagreements are not just in the relative perceptions of organizational variables but in what variables are most influential in effecting a key variable.

A recent study of the Organizational Context for Teaching and Learning identified consistent differences between faculty and administrator perceptions of organizational variables both within institutions and across three types of institutions. The purposes of this research paper are twofold: to examine the pattern of differences between faculty and administrator perceptions of their institutions as organizations and to investigate the relationships among organizational variables that faculty and administrators perceive in order to determine whether they have, not just differing views, but different "implicit models" of how their institutions function. The focus is on organizational dimensions that examine differences in administrator and faculty perceptions of their institution's academic purpose and institutional culture, its organizational and administrative climate, and the faculty motivational climate for undergraduate education and teaching. The paper addresses the following questions: 
1. Do faculty and academic administrators' differing perceptions of their institution's academic purpose and culture, organizational and administrative climate, and faculty motivational climate for undergraduate education reflect a consistent descriptive pattern that suggests a different implicit organizational model?

2. Are these differences in academic administrator and faculty perceptions affected by the type of institution in which they work?

3. To the extent that there are consistent differences, do faculty and administrators have different implicit models of how their institutions function (i.e., do they see different organizational variables as predictors of faculty motivational climate)?

\section{CONFLICTING VIEWS OF THE ORGANIZATIONAL CONTEXT}

Numerous studies of organizational phenomena in colleges and universities present differences in faculty and administrative beliefs about and perceptions of their institutions, both within and across institutional types. They are based largely on faculty perspectives (Austin and Gamson, 1983; Bowen and Schuster, 1986; Rice and Austin, 1988); research on what administrators believe about faculty is much less extensive (Blackburn, Pitney, Lawrence, and Trautvetter, 1989).

A few recent studies underscore the differences in faculty and administrator beliefs and perceptions of their organizations. In a study of individual perceptions of organizational goals in higher education, Birnbaum (1987) did a content analysis of the responses of senior administrators and faculty leaders to open-ended interviews on 32 campuses. He concludes that there is great inconsistency toward goals among institutional participants, with respondents in universities and community colleges expressing the least consistency in articulation of the goals of their institutions. In a national sample of college and university presidents and faculty officers, Neumann (1987) found that presidents and faculty officers disagreed on the attributes of good faculty leadership. Blackburn, Lawrence, and Associates (1990), in a representative national survey of faculty and administrators, found consistent differences between faculty and administrator views of the organization on several dimensions, including views of the organizational climate, academic workplace, and administrative supportiveness.

These studies reflect the reflect the results of a comprehensive literature review that concludes: (1) that there are faculty and administrator differences on many separate organizational variables, (2) that these differing perspectives occur in all institutional types, (3) that there are differences by institutional type, and (4) that those differences may be counterproductive. The literature is less clear on whether there is a consistent pattern of differing faculty and adminis- 


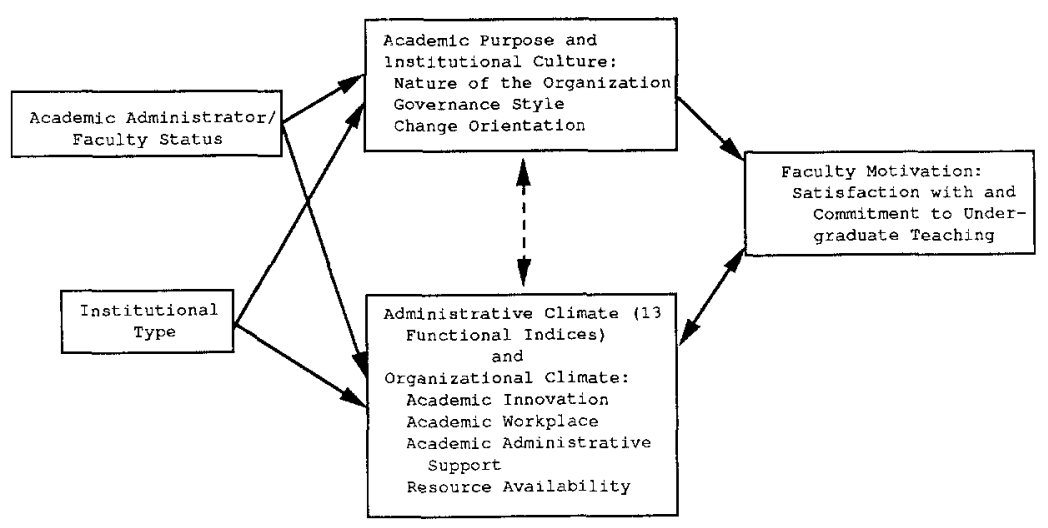

FIG. 1. Theoretical model.

trative views across several variables. No study was identified that examined the degree to which faculty and administrators see different patterns of variable interactions that reflect different "implicit models" of organizational functioning.

\section{CONCEPTUAL FRAMEWORK}

The conceptual framework for this research focuses on faculty and administrative perceptions of the organizational and administrative environment for undergraduate teaching and learning on their campus. Figure 1 depicts the framework for this study. The model focuses on three broad categories of organizational variables. Faculty Motivation toward undergraduate teaching is seen as the primary dependent variable category. The institution's Academic Purpose and Institutional Culture and its Organizational and Administrative Climate are conceived as the primary intervening variable categories. Since the study is based on individual survey responses and seeks to examine differing patterns, the respondents' Faculty or Administrator Status and the Institutional Type in which they reside are the primary independent or conditioning variables. The implicit assumptions of this model are that the institution's academic purpose and culture and its perceived organizational and administrative climate influence how faculty feel about their work and that this motivational or psychological climate is an effective predictor of faculty performance. (This study did not provide actual measures of faculty teaching performance. Student learning outcomes are, of course, the desirable dependent variable but common measures were not available for interinstitutional comparison.) 


\section{Culture and Climate: A Distinction}

Before discussing the variable categories in the model, a critical distinction in this conceptual framework is between organizational culture and climate. Although culture and climate are often used interchangeably, these concepts have varying definitions. For the purpose of this study, culture is defined as:

The deeply embedded patterns of organizational behavior and the shared values, assumptions, beliefs, or ideologies that members have about their organization or its work.

\section{Climate is:}

The current, common patterns of important dimensions of organizational life or its members' perceptions of and attitudes toward them.

Several dimensions help highlight the definitional distinction (for a thorough discussion of the distinction see Peterson and Spencer, 1990). Culture represents a holistic perspective while climate is focused on more specific phenomena. Culture is more embedded and less malleable.

Organizational culture focuses on those primary patterns of behavior that reflect deeply embedded values, beliefs, and assumptions that members share about their institutions and that make it distinctive. Climate, on the other hand, can focus on common perceptions of many different organizational phenomena (Allaire and Firsirotu, 1984). Further, because measures of climate focus on organizational phenomena, which are more specific and objective than those of culture, the participants' views of the organizational climate are based on more explicit content and are more easily discerned. The embedded assumptions shared by members of the organization are based more on the implicit content of culture, which is more difficult to identify. Finally, culture may be distinguished from climate by its continuity and resistance to change. As ephemeral and transient changes occur in the organization, participants' perceptions of the climate often change. Organizational culture, on the other hand, represents values closely held, less easily forsaken, and thus, it has more continuity over time. Culture has often been compared to the seasons and climate to the daily weather.

In essence, culture represents those aspects of organizational and higher educational life that provide important meaning to our life and work in and for the institution whereas climate is more akin to changing conditions around us. For example, an institution's faculty could believe strongly in their institution's and their own commitment to a highly individualized pattern of undergraduate education or close student-faculty community (culture). Yet, they could also have very differing views of the institution's support for this pattern of undergraduate education depending on leadership, resources, and curricular requirements 
(climate) that changed more often while the cultural belief (meaning) continued.

\section{Individual Variables}

Faculty versus administrative status is the key independent or conditioning variable in which this study is interested. The critical nature of this distinction and its relationship to measures of organizational culture, climate, and motivational variables were discussed earlier.

A substantial amount of research exists regarding the relationships between individual variables including age, gender, education, and position on both perceived and psychological climate (Moussavi, Jones, and Cronan, 1990; James and Jones, 1974; Jones and James, 1979). Specific differences in perceptions of psychological climate were found for faculty by gender (Thoreson et al., 1990). Austin and Gamson (1983) found that individual characteristics such as age, stage in career, and gender may predict faculty members' perceptions of the academic workplace and their commitment to undergraduate education. Since age, gender, and degree levels were not found to influence other variables in preliminary analyses for this study, only faculty and administrative status were included as the key status variable.

\section{Institutional Type}

Other studies have shown substantial variation on academic purpose, institutional culture, organizational climate, and even teaching-learning performance by institutional type (e.g., Martines, 1985; Cardozier, 1984; Howell and Edison, 1985). Thus, its effects as an independent or conditioning variable must be examined and controlled to understand the influence of faculty and administrator status.

\section{Academic Purpose and Institutional Culture}

While higher education studies have shown some differences in institutional purpose and culture by institutional type, most studies of institutional culture study culture for its own sake (Peterson and Spencer, 1990). They attempt to understand its nature, its development, or to gain holistic insight into the institution rather than to treat it as a variable affecting or affected by other variables (e.g., Clark, 1970; Chaffee and Tierney, 1988; Tierney, 1989). Yet it is widely assumed that an institution with a strong culture attracts members and enhances their motivation, which makes it central as a key variable in this study.

While there is a preference in the literature for ethnographic, qualitative studies when examining culture in the work environment, Schein (1985) pre- 


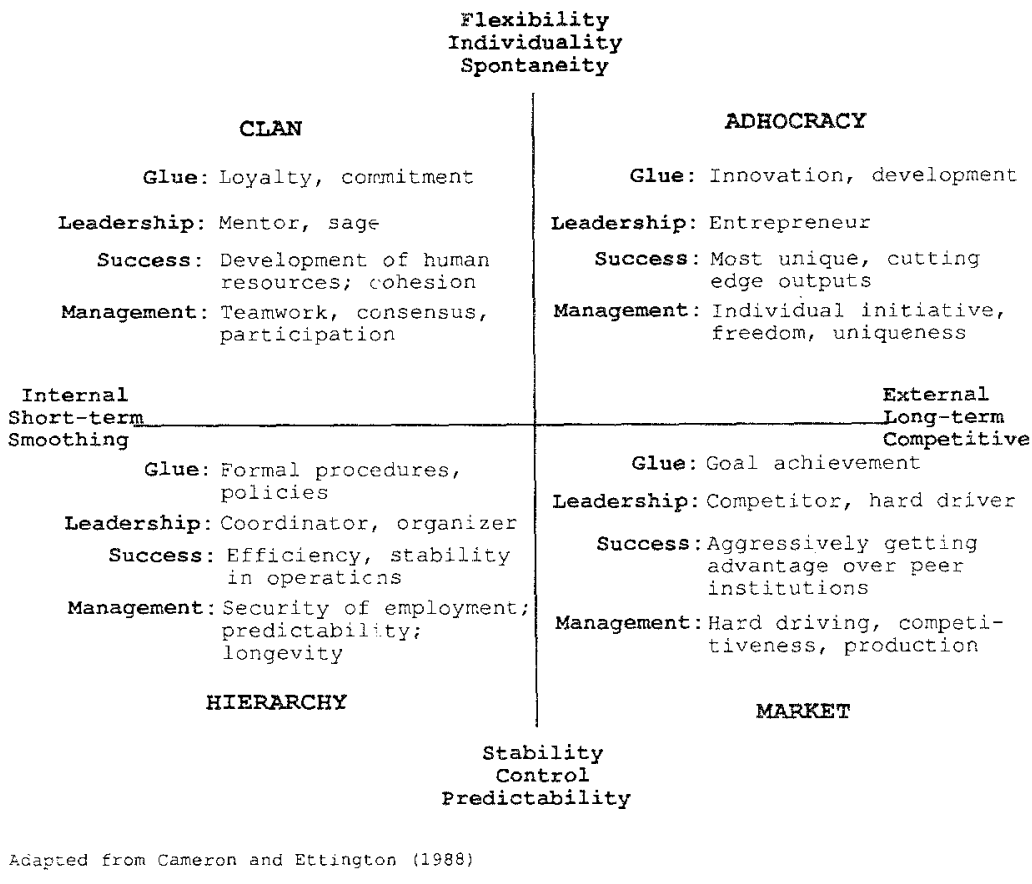

FIG. 2. Cultural models of organizations.

sents an opposite perspective and differentiates the views of the "ethnographer" from those of the "clinician." He dismisses qualitative results because of the unavoidable bias of the researcher. While the large study that is the source of this paper incorporates qualitative and quantitative methods, this paper considers only the quantitative data on culture.

The higher education literature suggests four major content dimensions of culture that are often used to study participants' beliefs about their institution and that seem to provide a central sense of meaning in a college or university: the institution's Academic Purpose, the nature of its Organization Culture, its Academic Governance Style, and its Organizational Change Orientation.

The Nature of Organizational Culture typology in this study is based on a framework developed by Cameron and Ettington (1988) that uses four elements (dominant characteristics, leadership style, criteria of success, and management style) to examine culture on two primary dimensions: internal-external orientation and emphasis on flexibility-stability. The resulting culture types are "clan or teamwork" (internal/flexible), "hierarchy or formal/rational" (internal/stable), "market" (external/stable), and "adhocracy or innovative" (external/flexible). (See Figure 2.) 


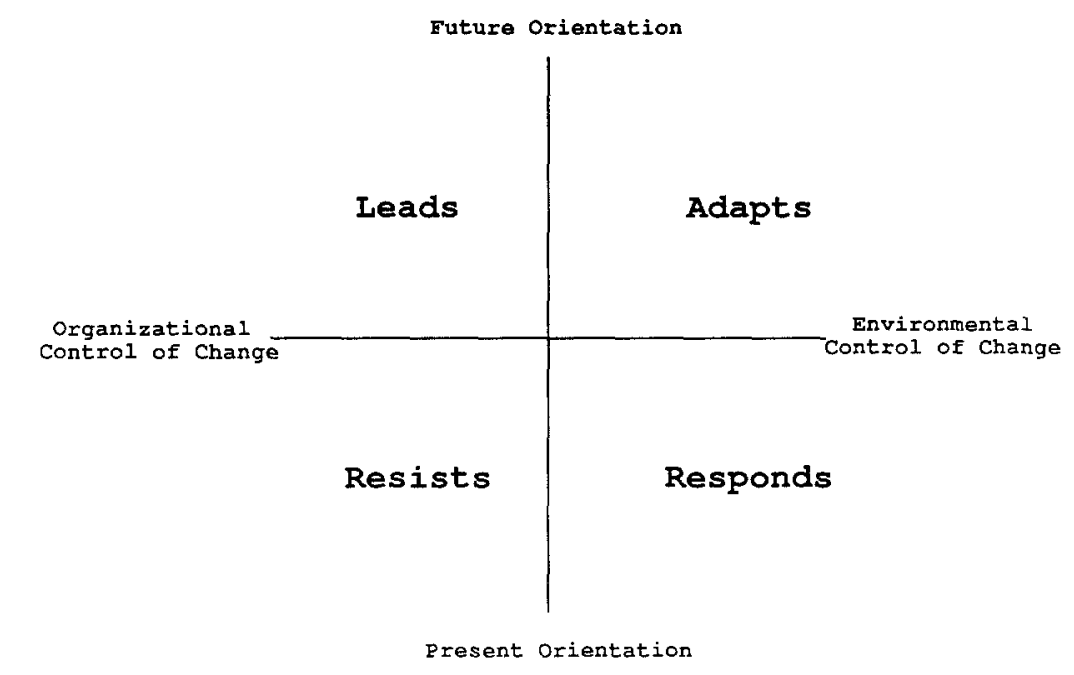

Petezson et al. (1978)

FIG. 3. Institutional change orientation.

The Academic Purpose typology addresses the primary purpose of undergraduate education and is drawn from literature reviews and instruments developed at NCRIPTAL (Peterson et al., 1991). They are: improving society: educating students who contribute productively, emphasizing general or liberal education, clarifying student values, and enhancing student intellectual skills.

The Governance Styles typology is also drawn from a NCRIPTAL literature review and instrument development (Peterson et al., 1986). They are: collegial, rational, political, autonomous, and anarchic.

The Change Orientation typology (Peterson et al., 1978) assesses the dimensions of future versus current orientation of change strategy and internal organization versus external environment locus of control. The resulting typology indicates that institutions respond (current/organization), resist (current/environment), adapt (future/environment), or lead (future/organization). (See Figure 3.)

\section{Organizational and Administrative Climate and Faculty Motivation}

These two categories of variables highlight a second critical distinction in this conceptual framework between three constructs of climate (Peterson et al., 1986): the "perceived climate" of the social psychologist, the "psychological or felt climate" of the cognitive psychologist, and the "objective" climate of the organizational behaviorist. (Observed behavior is not a focus of this study.) 
The perceived climate reflects members' shared common perception of the "patterns of organizational behavior." It usually focuses on explicit organizational behavior or phenomena. The psychological, or felt, climate is the "shared sense of how members feel about their organizations or their roles in it." This differentiation of the climate concept allows us to measure and to interpret behavior in organizations more accurately.

"Organizational and Administrative Climate" in this framework includes members' perceptions of five types of organizational and administrative behavior related to undergraduate education in their institutions: the institutional emphasis on the Academic Management Policies or Practices in thirteen functional areas, on patterns of Academic Innovativeness, on the challenge of work and professional treatment in the Academic Workplace, on Academic Resource Availability, and on the degree of Academic Administrative Support. All of these factors have been identified in the literature, as related to faculty motivation or performance (Blackburn, Pitney, Lawrence, and Trautvetter, 1989).

"Faculty Motivational Climate," the dependent variable in this framework, is defined as the faculty member's psychological or felt climate. It focuses on measures of Faculty Satisfaction with and Commitment to Undergraduate Education. Respondents were asked to indicate both personal and peer perceptions of these dimensions. The importance of this set of dependent variables is highlighted by Blackburn, Pitney, Lawrence, and Trautvetter's (1989) finding that faculty satisfaction and commitment to teaching are related to improved teaching performance.

\section{METHODOLOGY}

Three community colleges, three private liberal arts colleges, and four comprehensive universities participated in a study of the Organizational and Administrative Context for Teaching and Learning conducted at the National Center for Research to Improve Postsecondary Teaching and Learning (NCRIPTAL), the setting for this research. These institutions were selected from a population of 1053 institutions that responded to an earlier national survey of "Academic Management Practices" that was sent to 2300 institutions of postsecondary education with undergraduate programs. The 10 institutions reported a broad array of academic management practices existing on their campuses and an institution-wide effort to improve undergraduate education. The Community Colleges varied in urban-rural location while the Liberal Arts and Comprehensive institutions represented both urban-rural location differences and differing selectivity.

The data used for this paper are from a survey instrument, the Organizational Climate for Teaching and Learning (OCTL), developed at NCRIPTAL. The survey included sections measuring the institutional culture, organizational and administrative climate for undergraduate teaching and learning, and faculty 
motivation. It was used as a means of providing corroborating data for case studies of the ten institutions. The survey was given to all academic administrators and tenure-track faculty with appointments greater than 50 percent at all ten institutions. The overall response rate was 50 percent. A total of 1123 faculty responses and 381 administrator responses were received.

The Organizational Climate Survey instrument consists of 164 items in 9 sections. Institutional culture was measured by four indices of Organizational Culture and 14 discrete items measuring Academic Purpose, Academic Governance Style, and Educational Change. These are based on the conceptual framework from which they were created and not on factor analysis. Factor analysis with varimax rotation was used to identify 20 Organizational and Administrative Climate and 4 Faculty Motivation factors for this analysis. All statistical analyses were conducted using SPSSx. Each item was included in the factor cluster in which it had the highest loading, providing its factor loading was greater than .40 and the item made conceptual sense in the new index. Culture and climate indices were created based on the average value of all items included in the index. The alpha coefficients of reliability for the 24 indices ranged from .65 to .85 . These 14 items and 28 indices serve as variables and fall into three broad categories that are the conceptual framework for this study. (See Table 1 for a list of all indices and reliabilities.)

To measure the Academic Purpose and Institutional Culture quantitatively, ipsative measures were used. Respondents distributed 100 points over four or five response items on dimensions measuring Academic Purpose (5 items), Organizational Culture (4 indices) Academic Governance Style (5 items), and Educational Change Orientation (4 items) to indicate the "degree to which the item characterized their institution." We believe they provide a better understanding of the degree to which personal values and beliefs are strongly held than would have been possible with simple Likert-scaled items. The trade-off for better intraindividual discrimination is the set of well-documented problems associated with the statistical analysis of nonindependent measures (e.g., Clemans, 1966; Davis and Chissom, 1981; Johnson, Wood, and Blinkhorn, 1988). However, Tamir and Lunetta (1977) found that "When ipsative procedures are preferred on the ground of construct validity . . ., the danger of distorted relationships is not as severe as might have been expected" (p. 92). As noted above, the ipsative data items were assigned to indices for conceptual reasons, not through factor analysis.

To measure Organizational and Administrative Climate, respondents reported their perceptions of the "institution's emphasis on policies, practices or processes supporting undergraduate education" on a 5-point Likert scale of "None" (1) to "Very Strong" (5). Organizational and Administrative Climate indices include measures of Academic Management Climate (13 indices), Academic Innovation ( 1 index), Academic Workplace ( 2 indices), Administrative Support ( 2 indices), and Resource Availability ( 2 indices). 
TABLE 1. Reliabilities of the Purpose, Culture, Climate, and Motivational Indices

\begin{tabular}{lc}
\hline Indices & Alphas \\
\hline
\end{tabular}

1. Academic Purpose and Institutional Culture

A. Nature of the Organizational Culture

1. Teamwork

2. Innovation $\quad .72$

3. Rational

4. Market

B. Academic Purpose

1. General Improvement of Society*

2. Contribute Productivity to Society*

3. General/Liberal Education*

4. Individual Values Clarification*

5. Enhance Individual Thinking Skills*

C. Academic Governance Style

1. Collegial*

2. Formal/Rational*

3. Autonomous/Loosely Coordinated*

4. Anarchic*

5. Political

D. Educational Change Orientation

My institution
1. Leads*
2. Adapts*
3. Responds*
4. Resists*

II. Organizational and Administrative Climate

E. Academic Management Climate

1. Educational Mission and Goals

2. Academic Planning

3. Governance

4. Resource Allocation

5. Communication/Information

6. Student Recruitment and Enrollment Mgt

7. Academic, Curricular, and Program Mgt

8. Educational Technology

9. Faculty and Instructional Development

10. Faculty Selection, Evaluation, and Reward

11. Student Academic Support Services

12. Student Entry Assessment

13. Student Outcomes Assessment

F. Academic Innovation

1. Academic Innovation 
TABLE 1. (continued)

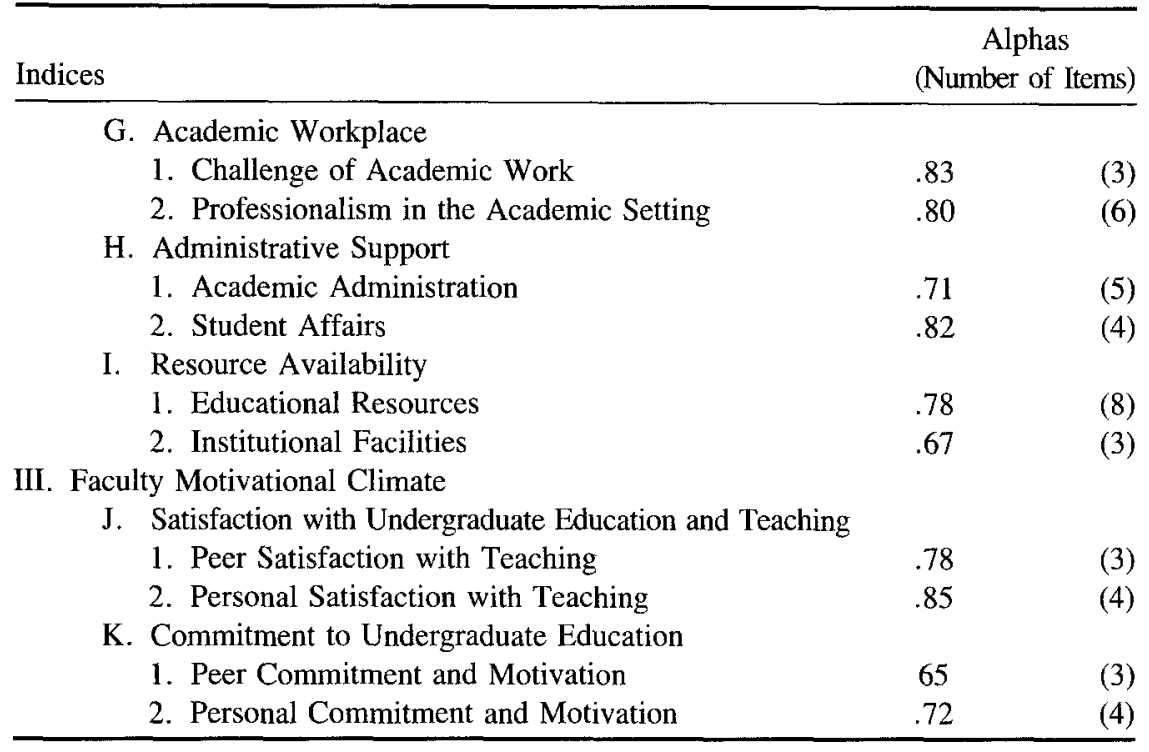

*Single-item variables.

For a complete definition of all indices and a copy of the OCTL survey instrument, see: M. Peterson et al., Assessing the Organizational and Administrative Context for Teaching and Learning. Ann Arbor, MI: NCRIPTAL, 1991.

Finally, to measure the Faculty Motivational Climate, respondents used a 5-point Likert scale to indicate their own and their perception of their peers' "Satisfaction with and Commitment to Undergraduate Education at their institution." Four indices measuring Personal and Faculty Colleague Satisfaction with Undergraduate Education (2 indices) and Personal and Faculty Colleague Commitment to Undergraduate Education ( 2 indices) emerged. The two measures dealing with "Personal Satisfaction" and "Personal Commitment" are inappropriate for administrators and were not included in this analysis.

\section{PATTERNS OF DIFFERENCES}

\section{Analysis}

Analyses of variance was used to determine differences between administrator and faculty status and among institutional types for all respondents on the measures of Academic Purpose and Institutional Culture, Organizational and Administrative Climate, and Faculty Motivational Climate (see Table 2). Additional analyses compared faculty versus administrator status within institutional type: community college, liberal arts, and comprehensive university (see Table $3)$. 


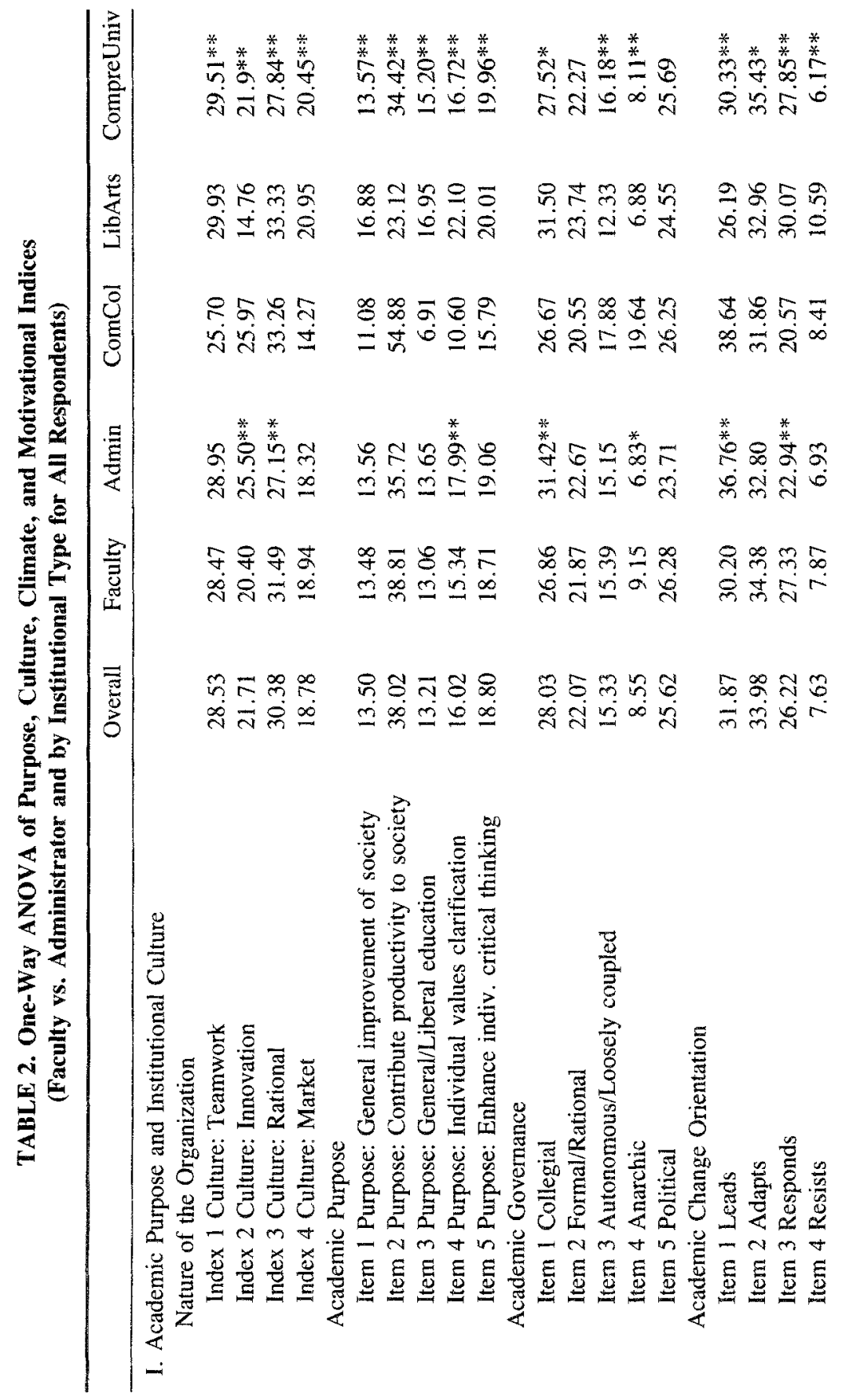




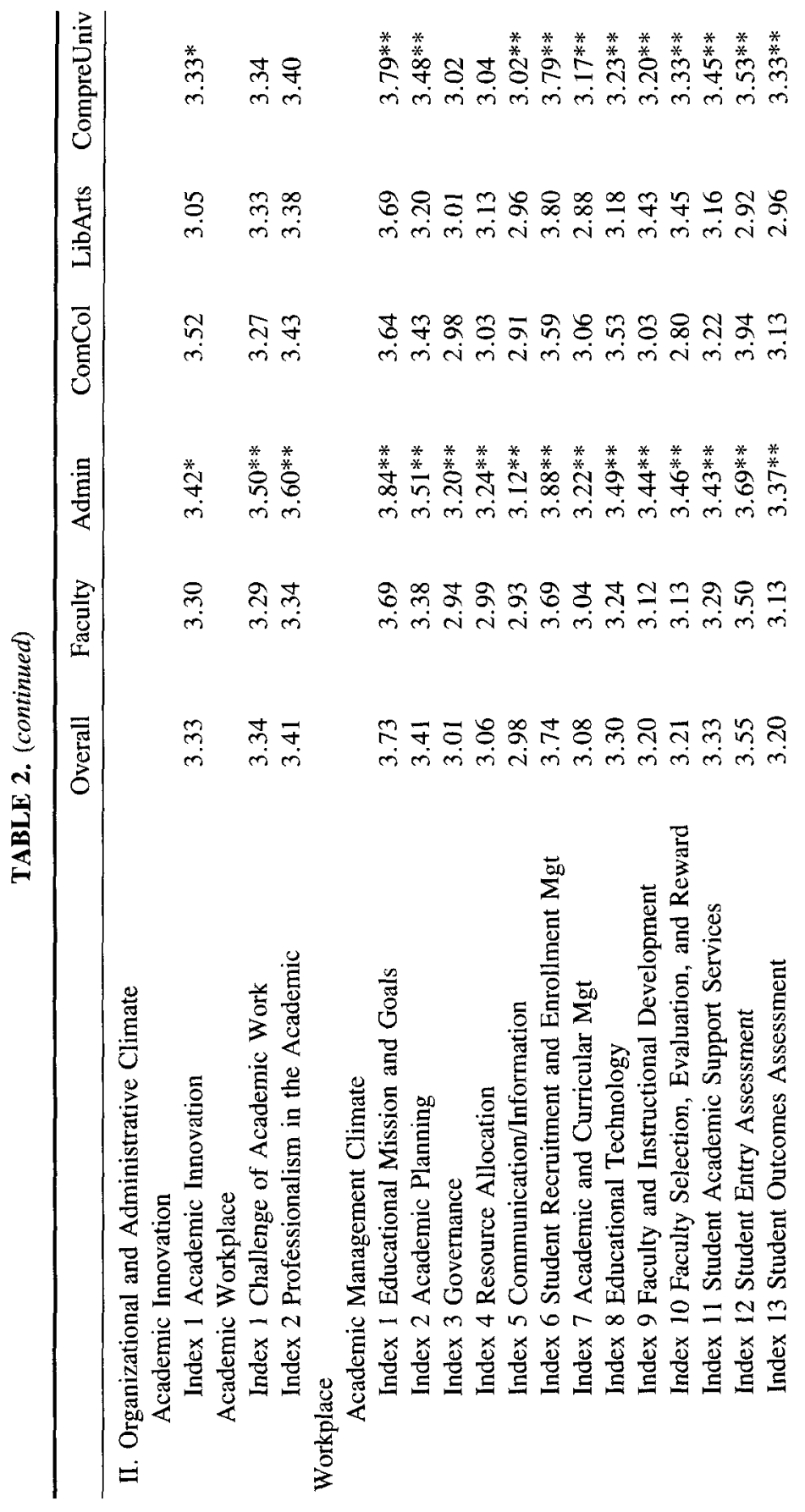




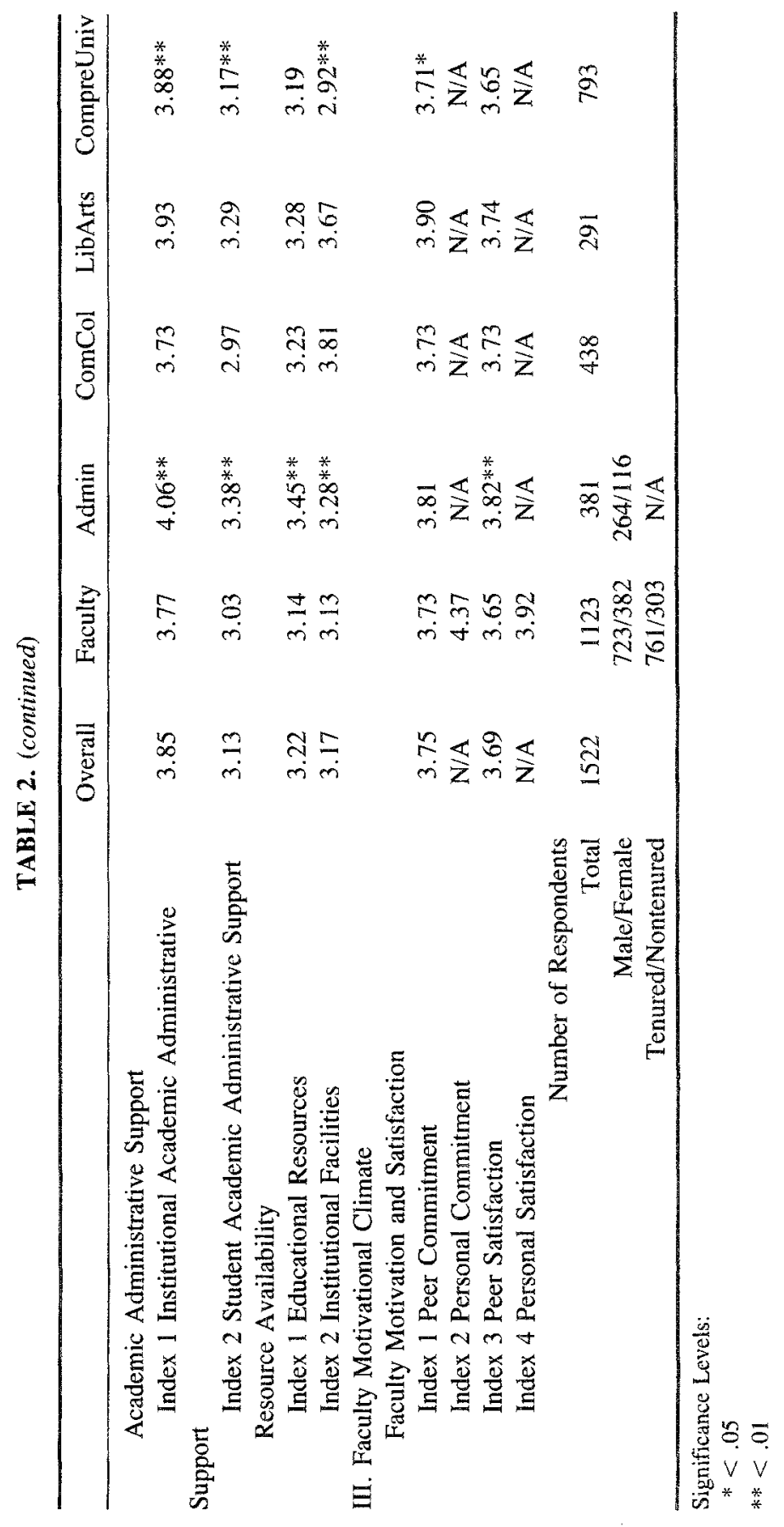




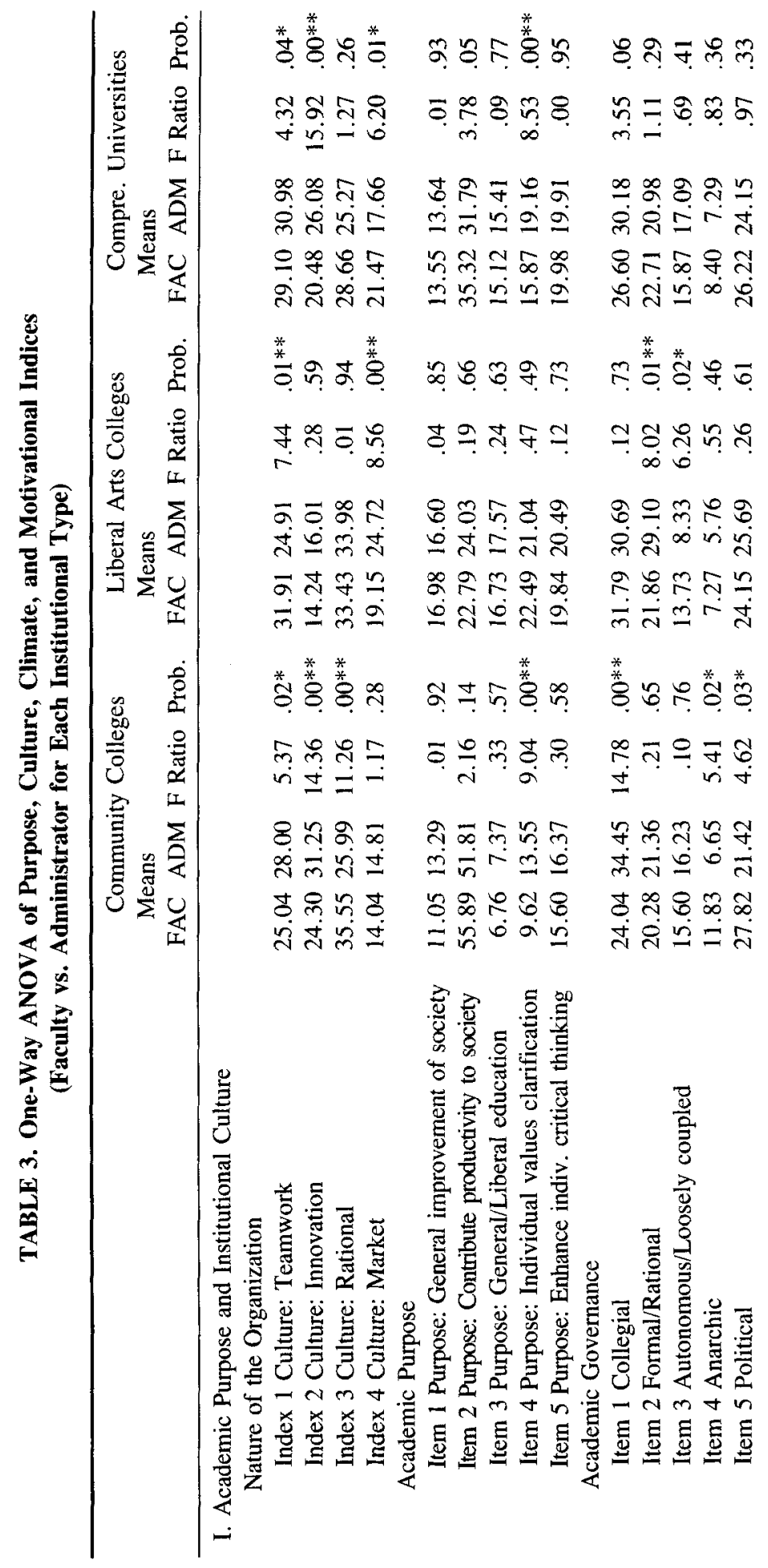




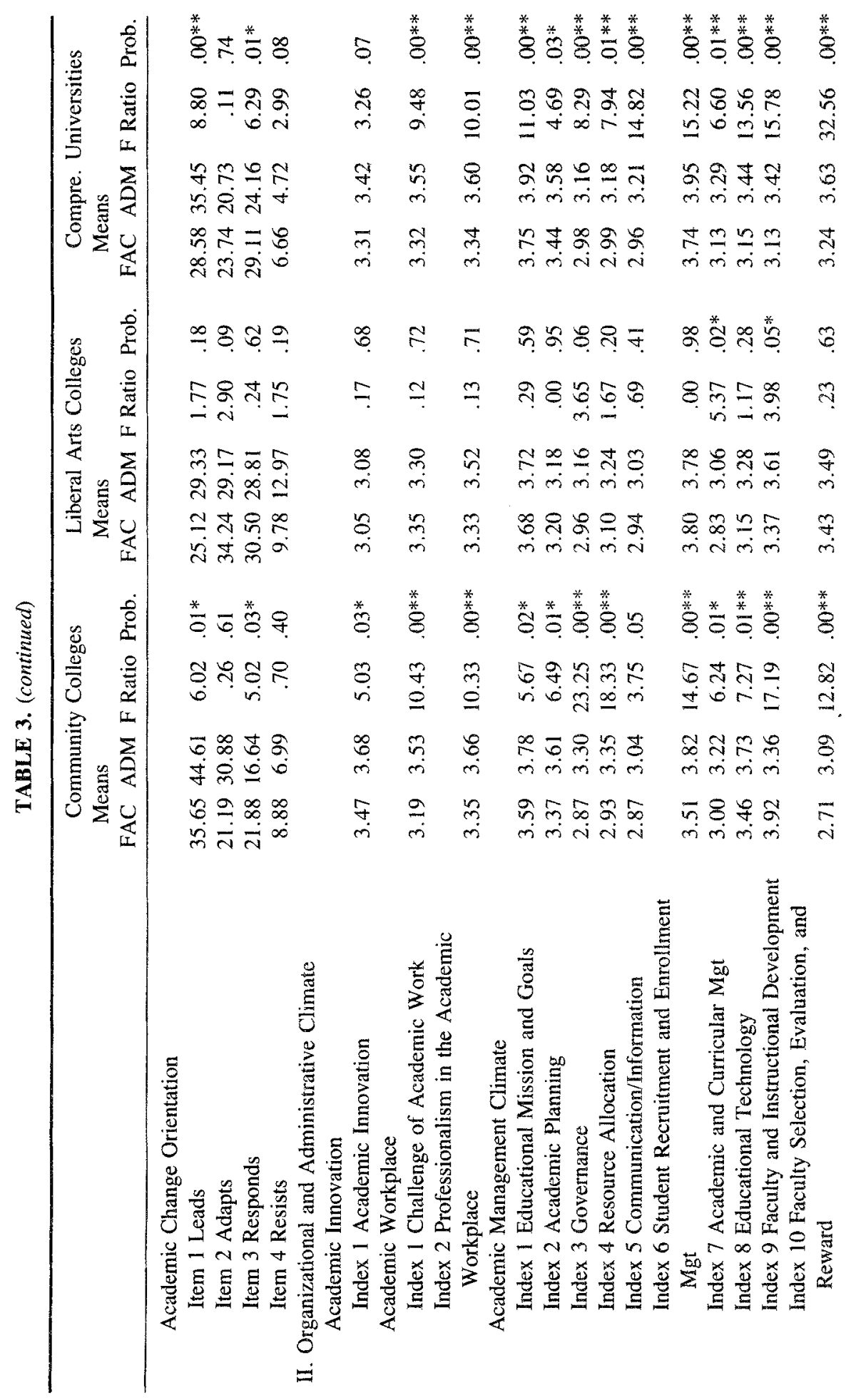




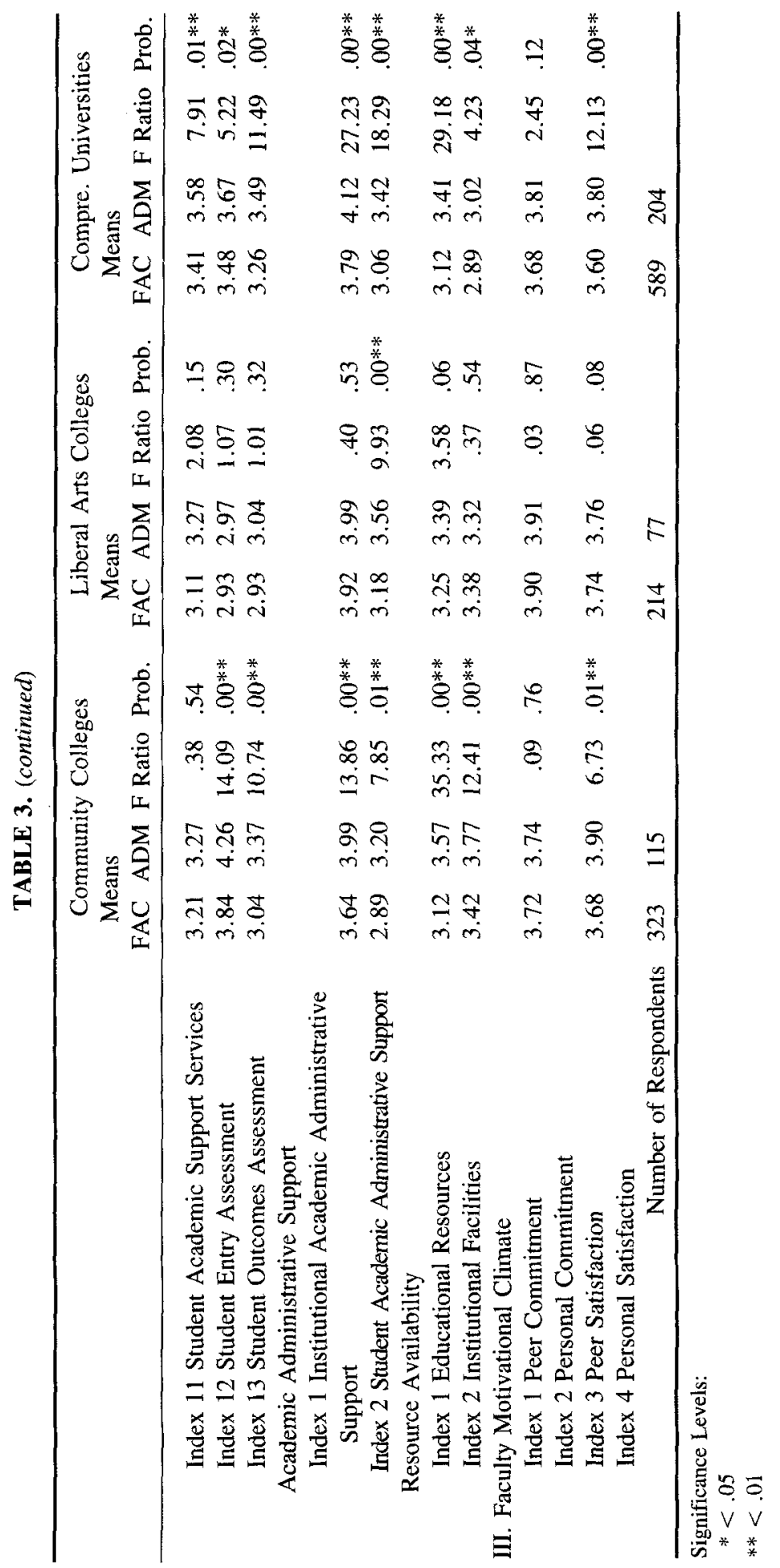




\section{Results and Discussions}

The analysis of variance by faculty and administrator respondent and by institutional type showed no significant differences on Faculty Commitment to Undergraduate Education (See Tables 2 and 3). On the other hand, the variance on Faculty Satisfaction with Undergraduate Teaching was significantly different for faculty and administrators overall and between the community college and comprehensive university respondent group and those in private liberal arts colleges. This suggested that institutional type was an important control variable in predicting the satisfaction variable.

\section{The Effects of Institutional Type}

The analysis of variance by institutional type for all respondents revealed great diversity in the perceptions of community college, liberal arts college, and comprehensive university respondents on the Academic Purpose and Institutional Culture, Organizational and Administrative Climate, and Faculty Motivation Indices (see Table 2). Significant differences at the .05 level occurred on 34 of the 40 indices. Such differences indicate that institutional type may confound the results of other analyses. However, the results of a two-way analysis of variance of institutional type and faculty or administrator status on all indices showed that only four variables displayed significant interaction effects: Teamwork as the Nature of the Organization, Collegial Governance, Student Entry Assessment, and Institutional Facilities. Thus, any confounding effects of institutional type should be minimal. While these differences can lead to interesting insights about differences in implicit organizational models by institutional type, the small sample of institutions makes any analysis speculative.

\section{Faculty and Administrator Differences}

The analysis of the variance between all faculty and administrator respondents showed significant differences at the .05 level on 28 of the 40 indices in this study (see Table 2). More agreement occurred on the Institutional Culture indices than on the Organizational and Administrative Climate indices. Faculty and administrators differed on only 7 of 18 indices of Academic Purpose and Institutional Culture but on all 20 of the Organizational and Administrative Climate indices. A statistically significant difference occurred on one Motivational Climate Index, but the actual differences were small.

In the Academic Purpose and Institutional Culture indices, administrators, as opposed to faculty, see greater emphasis on values clarification as an educational purpose, governance as more collegial (and less anarchic), and their institutions as leading (not responding), more innovative, and less rational. Among the Organizational and Administrative Climate indices, administrators 
see their institutions placing greater emphasis on all areas: academic management practices, support for academic innovation, having a challenging and professional work setting, having supportive administrators, and having more available educational resources and facilities. Interestingly, while administrators in these ten institutions see levels of Faculty Commitment to and Satisfaction with Undergraduate Education as high (as do faculty), they seem to have a much more positive or idealized view of their institutions as being more value oriented and collegial as well as more innovative than do faculty.

A clearer pattern emerges when we analyze faculty and administrator differences by institutional type (see Table 3 ). Community college faculty and administrators disagreed on 28 of the 40 indices used in the study and comprehensive university faculty and administrators disagreed on 26 of the 40 indices. Liberal arts participants, on the other hand, perceived differences on only 7 of those same measures. Community college faculty and administrators disagreed on 9 of 18 measures of Academic Purpose and Organizational Culture and on 18 of 20 measures of the Organizational and Administrative Climate. Comprehensive university faculty and administrators' perceptions disagreed less frequently on Academic Purpose and Organizational Culture indices (6/18) than on the Organizational and Administrative Climate indices (19/20).

In other words, community college faculty and administrators disagreed more than those in the other two institutional types both on Academic Purpose and Institutional Culture, and on Organizational and Administrative Climate dimensions. At the liberal arts colleges, faculty and administrators in the study are largely in agreement on both. Faculty and administrators at comprehensive universities differ to some degree on Academic Purpose and Institutional Culture but disagree on all Organizational and Administrative Climate measures.

The direction of faculty and administrator responses reflects that for all respondents, perceptions vary by institutional types. In the liberal arts colleges, there is strong agreement on the purposes, culture, and climate patterns. Community college administrators saw their institutions as more concerned about values (still low) and perceive governance as collegial in an entrepreneurial and innovative setting, while their faculties were more likely to view governance as a political process in a more formal-rational organization. Comprehensive university administrators viewed their institutions as having a concern for values education and as leaders in undergraduate education in a more innovative teamwork-oriented institution; faculty see their institution as a responsive marketdriven place. Community college and comprehensive university faculty both exhibit lower means than their administrative colleagues on all the Organizational and Administrative Climate indices.

The highest agreement on Academic Purpose and Institutional Culture occurs in the liberal arts institutions, less occurs in the comprehensive, and the least agreement occurs in the community colleges. This supports the argument that commonality of purpose and strength of institutional culture is most likely in 
TABLE 4. Academic Purpose, Institutional Culture, and Organizational Climate as Predictors of Faculty Commitment to Improve Undergraduate Education (Regressions by Respondent Group)*

\begin{tabular}{|c|c|c|}
\hline Faculty & & Administrators \\
\hline $\mathrm{R}, 2$ & Institutional Culture & $\mathrm{R}, 2$ \\
\hline \multirow[t]{2}{*}{.007} & Purpose: Contribute productivity to society & \\
\hline & Purpose: Enhance indiv. critical thinking sk & .010 \\
\hline \multirow[t]{2}{*}{.044} & Governance: Collegial & \\
\hline & Governance: Political & .013 \\
\hline .101 & Change Orientation: Leads & .129 \\
\hline \multirow[t]{2}{*}{.013} & Culture: Teamwork & \\
\hline & Culture: Rational & .020 \\
\hline \multirow[t]{3}{*}{.166} & Total & .178 \\
\hline & Organizational Climate & \\
\hline & Challenge of Academic Work & .031 \\
\hline .297 & Institutional Academic Administrative Support & .299 \\
\hline .057 & Educational Resources & \\
\hline .013 & Educational Mission and Goals & \\
\hline \multirow[t]{2}{*}{.007} & Faculty and Instructional Development & \\
\hline & Faculty Selection, Evaluation, and Reward & .067 \\
\hline \multirow[t]{3}{*}{.373} & Total & .397 \\
\hline & Culture \& Climate & \\
\hline & Challenge of Academic Work & .031 \\
\hline .297 & Institutional Academic Administrative Support & .299 \\
\hline .057 & Educational Resources & \\
\hline .013 & Educational Mission and Goals & \\
\hline \multirow[t]{2}{*}{.007} & Faculty and Instructional Development & \\
\hline & Faculty Selection, Evaluation, and Reward & .067 \\
\hline .373 & Total & .397 \\
\hline
\end{tabular}

*Based on stepwise regressions. Variable's contribution to $\mathrm{R}_{\wedge} 2$ shown only for those at the .05 level.

the liberal arts colleges, and least clear in the community college or larger public institutions. The degree of faculty and administrator consensus on the varied dimensions of climate in the Liberal Arts and the sizable differences in both the Community Colleges and Comprehensive Universities may suggest either the importance of culture in supporting cohesive climate or the effect of institutional differences.

\section{PREDICTING MOTIVATIONAL CLIMATE: IMPLICIT MODELS}

\section{Analysis}

To go beyond the descriptive differences in the way they viewed their institutions and to investigate whether faculty and administrators held different im- 
plicit organizational models (i.e., saw different variables associated with the dependent variables), a series of regressions was run. Because of the strong influence of institutional type (Table 2), dummy-coded institutional-type variables were used to partial out the influence of institutional type.

Using only faculty response data, each of the two dependent variables (Faculty Commitment to and Faculty Satisfaction with Undergraduate Teaching) were regressed separately against each of the two categories of independent variables (Academic Purpose and Institutional Culture, and Administrative and Organizational Climate). Separate regressions were run because of limitations in the sample size. Then the dependent variables were regressed once more, in a stepwise regression, against all the indices (Institutional Type, Academic Purpose and Institutional Culture, and Organizational and Administrative Climate) that were statistically significant predictors in the previous regressions. The whole sequence was repeated using the administrator data. Table 4 displays the results of the separate regressions for faculty and for administrative respondents predicting Faculty Commitment. Table 5 displays the same information for Faculty Satisfaction. Only the indices that made statistically significant contributions (.05 level) to explaining the variance $\left(R^{2}\right)$ are shown.

\section{RESULTS AND DISCUSSION}

The previous analysis of patterns of differences in faculty and administrator perceptions of the academic purposes, organizational culture, and organizational and motivational climate of their institutions suggests that faculty and administrators may see different "implicit descriptive models." However, it does not make clear whether they have different "implicit causal models" of how the institution actually functions. If faculty and administrators have different mental models of how their institutions function, then one would expect different organizational variables to predict the Motivational Climate (dependent) variables in this study. The regression analysis examined these dynamics.

\section{Commitment}

The regression of the Academic Purpose and Institutional Culture indices against the Faculty Commitment to Undergraduate Education (Table 4) accounted for only 17 percent of the variance for faculty and 18 percent of the variance for administrators. The primary contributing variables for both respondent groups was Academic Change Orientation (Institution is a "leader"), which explained 10 percent of the variance in the faculty model and 13 percent in the administrator model.

The regression of Faculty Commitment against the Organizational and Administrative Climate indices accounted for 37 percent of the variance for faculty 
TABLE 5. Academic Purpose, Institutional Culture, and Organizational Climate as Predictors of Faculty Satisfaction with Undergraduate Education

(Regressions by Respondent Group)*

\begin{tabular}{|c|c|c|}
\hline Faculty & & Administrators \\
\hline $\mathrm{R}, 2$ & Institutional Culture & $\mathrm{R}, 2$ \\
\hline .005 & Purpose: Contribute productivity to society & \\
\hline \multirow[t]{2}{*}{.014} & Governance: Collegia! & \\
\hline & Governance: Political & .052 \\
\hline .101 & Change Orientation: Leads & .149 \\
\hline $.033(-)$ & Change Orientation: Resists & \\
\hline \multirow[t]{2}{*}{.145} & Culture: Teamwork & \\
\hline & Culture: Rational & .030 \\
\hline \multirow[t]{3}{*}{.298} & Total & .231 \\
\hline & Organizational Climate & \\
\hline & Professionalism in the Academic Workplace & .241 \\
\hline .030 & Institutional Academic Administrative Support & .030 \\
\hline .013 & Educational Resources & \\
\hline \multirow[t]{2}{*}{.285} & Educational Mission and Goals & .011 \\
\hline & Academic Decision Making & .059 \\
\hline .068 & Faculty and Instructional Development & \\
\hline \multirow[t]{2}{*}{.397} & Total & .340 \\
\hline & Culture \& Climate & \\
\hline .003 & Governance: Collegial & \\
\hline .006 & Change Orientation: Leads & \\
\hline .004 & Change Orientation: Resists & \\
\hline \multirow[t]{3}{*}{.022} & Culture: Teamwork & \\
\hline & Culture: Rational & .019 \\
\hline & Professionalism in the Academic Workplace & .241 \\
\hline .030 & Institutional Academic Administrative Support & .030 \\
\hline .015 & Institutional Resources & \\
\hline \multirow[t]{2}{*}{.285} & Educational Mission and Goals & \\
\hline & Academic Decision Making & .059 \\
\hline .068 & Faculty and Instructional Development & \\
\hline .433 & Total & .348 \\
\hline
\end{tabular}

*Based on stepwise regressions. Variable's contribution to $\mathrm{R}_{1} 2$ shown only for those at the 05 level.

and 40 percent for administrators. In both sets of results, emphasis on Institutional Academic Administrative Support (i.e., "support for improving undergraduate education" by board members, the president, the executive officers, deans, and department chairs) was the major contributing variable, predicting 30 percent of the variance in both respondent models. The second variable of consequence is emphasis on the availability of Educational Resources (for 
Teaching) in the faculty model (6\% of variance in $R^{2}$ ) and on Faculty Selection, Evaluation, and Reward (7\% of variance in $R^{2}$ ) in the administrative model. Each makes a very small contribution, however.

In the combined regression, the influence of the larger climate predictors superseded the influence of the culture indices. These results are the same for both respondent groups, which suggests that faculty and administrators have a similar "implicit" organizational model of how the institution functions. The notion is a "top down" model in which emphasis on "institutional academic administrative support" seems to reinforce "faculty commitment to undergraduate education." This is consistent with an institution whose members see it as a "leader" in undergraduate education. In a very minor way, faculty see the "availability of educational resources" as reinforcing their commitment while administrators see manipulation of "faculty selection, evaluation, and rewards for teaching" as reinforcing faculty commitment.

\section{Satisfaction}

The regression of Faculty Satisfaction with Undergraduate Education on the Academic Purpose and Institutional Culture indices yielded somewhat different predictors for faculty than for administrators (Table 5). The faculty model accounts for 30 percent of the variance and sees an organizational culture emphasizing "teamwork" (15\% of the variance) and an institutional change orientation emphasizing "leadership" in undergraduate education (10\% of the variance) as the key dynamics influencing faculty satisfaction. The administrative model accounts for only 23 percent of the variance with an institutional "leadership" orientation as the major contributor (15\% of the variance) and with "political" governance style in a "rational" organization as minor influences.

The results of the regression of Faculty Satisfaction with Undergraduate Education on the Organizational and Administrative Climate indices suggest further distinctions between faculty and administrators (Table 5). The faculty model accounts for 40 percent of the variance and sees an emphasis on "educational mission and goals" stressing undergraduate education as the primary variable (29\% of the variance) influencing Faculty Satisfaction with some contribution from an emphasis on "faculty and instructional development" (7\% of the variance). The administrative model accounts for 34 percent of the variance but sees an emphasis on "professionalism in the academic workplace" ( $24 \%$ of the variance) as the key contributing variable followed by an emphasis on "academic decision making" ( $6 \%$ of the variance).

As with the prediction of Faculty Commitment, in the combined model predicting Faculty Satisfaction, the influence of the climate predictors supersedes that of the purpose and culture indices (Table 5). The faculty model now accounts for 43 percent of the variance, with emphases on "educational mission 
and goals" stressing undergraduate education (35\% of the variance) and "faculty and instructional development" (7\% of the variance) as the primary predictors. The administrative model remains essentially unchanged stressing "professionalism in the workplace" (24\% of the variance) with an emphasis on "academic decision making" ( $6 \%$ of the variance).

The patterns in these regressions do suggest slightly different "implicit causal models" of the organizational dynamics affecting Faculty Satisfaction with Undergraduate Education. For faculty, an institution with a cultural belief that it employs "teamwork" in a climate that emphasizes "educational mission and goals" stressing undergraduate education (that is, one that appears to be consistent with a cohesive collegial model), appears to be one model that is related to Faculty Satisfaction. Administrators also have a model stressing a "leadership" role or culture but one in which a climate of "professionalism in the academic workplace" is the primary predictor of Faculty Satisfaction. There is seemingly less emphasis on teamwork and "educational mission and goals" for undergraduate education, and more reliance on a professional model of organization.

\section{CONCLUSIONS}

This paper began with three questions regarding differences in faculty and administrator perceptions of their academic organizational context. The results lead us to conclude that faculty and administrators do seem to differ consistently in their perceptions of Academic Purposes and Institutional Culture, of the Organizational and Administrative Climate, and of the Faculty Motivational Climate for undergraduate education. Administrators appear to reflect a more idealized view. They place more stress on values as the primary educational purpose, view the nature of the organization as slightly more entrepreneurial, see a more supportive organizational and administrative climate, and have a more favorable view of faculty motivation.

Regarding institutional type, faculty and administrator differences were more pronounced in the community colleges and the comprehensive universities than in the liberal arts colleges. Culture and climate were more distinctive, easier to identify, and more cohesive in the liberal arts colleges. In this small sample, institutional type was a slightly larger predictor of differences than faculty versus administrator status but did not eliminate the effects of role.

Finally, the regression analysis of faculty and administrative respondents on "faculty commitment to undergraduate education" suggested similar "implicit models." A similar analysis of "faculty satisfaction with undergraduate education" suggests slightly divergent "implicit models."

\section{Implications for Future Research}

Clearly the institutional sample size is too small for extensive generalizations about faculty and administrative differences, the implications of institutional 
type, and the existence of different models of organization. However, the significant contrasts in faculty and administrative perceptions in a consistent direction points to the need to examine the impact of such differences on other institutional variables. In addition, the variation in those patterns of difference by institutional type suggests the need for further study of these differences in perceptions of organizational culture and climate in a larger sample of institutions. Finally, the descriptive and relational evidence of possible different "implicit models" of organization among faculty and administrative constituents suggests a fruitful line of conceptual as well as practical research. Further, exploration of different "implicit models" by incumbents of more specific roles (e.g., student affairs and academic administrators, faculty in different fields, etc.) and by participants in different institutional types is needed.

\section{REFERENCES}

Allaire, Yuan, and Firsiruto, Mihaela E. (1984). Is "organizational culture" culture bound? Human Resource Management 25: 72-90.

Austin, Ann E, and Gamson, Zelda F. (1983). Academic Workplace: New Demands, Heightened Tensions. (ASHE-ERIC Higher Education Research Report No. 10. Washington, DC: Association for the Study of Higher Education.

Bensimon, Estella M. (1987, November). The meaning of "good presidential leadership": A Frame analysis. Paper presented at the annual meeting of the Association for the Study of Higher Education, Baltimore.

Birnbaum, Robert (1987, November). Individual preferences and organizational goals. Consistency and diversity in the futures desired by campus leaders. Paper presented at the annual meeting of the Association for the Study of Higher Education, Baltimore.

Blackburn, Robert T., Lawrence, Janet, and Associates (1990). Same Institution, Different Perceptions: Faculty and Administrators Report on the Work Environment. Publication of the National Center for Research to Improve Postsecondary Teaching and Learning. Ann Arbor, MI: The University of Michigan.

Blackburn, Robert T., Pitney, Judith A., Lawrence, Janet H., and Trautvetter, Lois (1989, March). Administrators' career backgrounds and their congruence with faculty beliefs and behaviors. Paper presented at the annual meeting of the American Educational Research Association, San Francisco.

Bowen, Howard R., and Schuster, Jack H. (1986). American Professors: A National Resource Imperiled. New York: Oxford University Press.

Cameron, Kim S., and Ettington, Deborah R. (1988). The conceptual framework of organizational culture. In John C Smart (ed.), Higher Education: Handbood of Theory and Research, vol. 6, pp. 356-396. New York: Agathon Press.

Cardozier, V. R. (1984). Upper-level colleges yesterday, today, and tomorrow. Educational Record 65(3): 30-35.

Chaffee, Ellen E., and Tierney, William G. (1988). Collegiate Culture and Leadership Strategies. New York: American Council on Education and Macmillan Publishing Co.

Clark, Burton, R. (1970). The Distinctive College: Antioch, Reed, and Swarthmore. Chicago: Aldine Publishing Co. 
Clemans, William V. (1966). An Analytical and Empirical Examination of Some Properties of Ipsative Measures. Psychometric Monograph, Number 14. Richmond, VA: The William Byrd Press, Inc.

Corson, John J. (1960). Governance of Colleges and Universities. New York: McGrawHill.

Davis, Todd M., and Chissom, Brad (1981, October). Factor analysis ( $R$-technique) of ipsatized data may be misleading. Psychological Reports 49(2): 643-647.

Howell, Joe A., and Edison, Donald R. (1985). The Idea of an Ideal Liberal Arts College. Lanham, MD: University Press of America.

James, L. R., and Jones, A. P. (1974) Organizational climate: A review of theory and research. Psychological Bulletin 81:1096-1112.

Johnson, Charles E., Wood, Robert, and Blinkhorn, S. F. (1988, June). Spuriouser and spuriouser: The use of ipsative personality tests. Journal of Occupational Psychology 6I(2): 153-162.

Jones, A. P., and James, L. R. (1979). Psychological climate: Dimensions and relationships of individual and aggregated work environment perceptions. Organizational Behavior and Performance 23:201-250.

Martines, Lauro (1985, Spring). Large and little school teaching: Reed College and UCLA. American Scholar 54: 194-203.

Moussavi, Farzad, Jones, Thomas W., and Cronan, Timothy P. (1990, April). Explaining psychological climate: Is perceptual agreement necessary? Journal of Social Psychology 130: 239-248.

Neumann, Anna (1987, November). Defining "good faculty leadership": Interpretations of professors and presidents. Paper presented at the annual meeting of the Association for the Study of Higher Education, Baltimore.

Peterson, Marvin W., and Spencer, Melinda G. (1990). Assessing academic culture and climate. In William G. Tiemey (ed.), Assessing Organizational Climate and Culture (New Directions in Institutional Research, No. 68), pp. 3-18. San Francisco: JosseyBass.

Peterson, Marvin, W., Blackburn, Robert, Gamson, Zelda F., et al. (1978). Black Students on White Campuses: The Impacts of Increased Black Enrollments. Ann Arbor, MI: Institute for Social Research.

Peterson, Marvin W., Cameron, Kim S., Mets, Lisa A., Jones, Phillip, and Ettington, Deborah R. (1986). The Organizational Context for Teaching and Learning: A Review of the Research Literature. Publication of the National Center for Research to Improve Postsecondary Teaching and Learning. Ann Arbor, MI: The University of Michigan.

Peterson, M. W., Cameron, K. S., Knapp, A., Spencer, M. G., and White, T. H. (1991). Assessing the Organizational Context for Teaching and Learning: An Institutional Self-Study Manual. The University of Michigan, Ann Arbor, MI: NCRIPTAL.

Rice, Eugene, and Austin, Ann E. (1988, March-April). High faculty morale: What exemplary colleges do right. Change 20:50-58.

Schein, Edgar H. (1985). Organizational Culture and Leadership: A Dynamic View. San Francisco: Jossey-Bass.

Tamir, Pinchas, and Lunetta, Vincent N. (1977, November-December). A comparison of ipsative and normative procedures in the study of cognitive preferences. Journal of Educational Research 71(2): 86-93.

Thoreson, Richard W., Kardash, Carol Anne M., Leuthold, David A., and Morrow, Kelly A. (1990). Gender differences in the academic career. Research in Higher Education 31(2): 193-209. 
Tichy, Noel (1983). Managing Strategic Change: Technical, Political, and Cultural Dynamics. New York: Wiley.

Tierney, William G. (1989). Curricular Landscapes, Democratic Vistas: Transformative Leadership in Higher Education. New York: Praeger.

White, Theodore H. (1990). Differences in faculty and administrator perceptions of their institutions: Implications for institutional performance. Unpublished doctoral preliminary examination. Ann Arbor, MI: University of Michigan.

Received January 2, 1991. 